\title{
Determination of Reducing Force of Litsea Cubeba Oil and Its Comparison with Antioxidant Capacity of Other Vegetable Oils
}

\author{
Fansheng Kong, Yanfen Zhang and Yongguang $\mathrm{Bi}^{\mathrm{a}^{*}}$ \\ College of Pharmacy, Guangdong Pharmaceutical University, Guangzhou 510006, Guangdong, \\ China \\ abiyongguang2002@163.com \\ ${ }^{*}$ Corresponding author:
}

Keywords: Litsea Cubeba Oil; Reducing Force; Antioxidant Activity; Comparison

\begin{abstract}
In this paper, the antioxidant activity of Litsea cubeba oil was determined by the reduction force method, and the reducing force of Litsea cubeba oil was compared with the three common oils of peanut oil, pepper oil and soybean oil. The results showed that the yield of Litsea cubeba oil was strong, and the reducing force of Litsea cubeba oil increased with the increase of the concentration of $8 \mathrm{mg} / \mathrm{mL}$ emulsion. Soybean oil and pepper oil compared to three commonly used oil, Litsea cubeba oil reduction force than peanut oil and soybean oil are strong, and pepper oil quite.
\end{abstract}

\section{Introduction}

Litsea cubeba is an important spice and biomass energy tree in southern China. In recent years, the international market Litsea cubeba oil prices soared, to the end of 2008 , with more than $70 \%$ citral alcapine oil price of more than 100,000 yuan per ton. China's annual output of Litsea cubeba oil up to 20000t, the world's largest producer and exporter, the annual export volume of about $3500 \mathrm{t}$, the products are exported to the United States, Japan, France, Germany, Switzerland, the Netherlands and other countries, renowned at home and abroad ${ }^{[1]}$.

Litsea cubeba seed is an important biomass energy, oil content of more than $40 \%$. With the rising international oil prices, biomass energy use more and more people pay attention. In recent years, China's efforts to develop biomass energy, but the focus on the development of farmland, such as the use of a large number of sugarcane, corn and other fermentation production of fuel ethanol, resulting in sugar and corn-based products, a substantial price increase, the National Development and Reform Commission Emergency stop a lot of corn, sugar cane production of fuel ethanol manufacturers ${ }^{[2]}$. With the increasing shortage of resources, only the use of natural resources and farmland crops have been far from meeting the needs of the market, which also for the mountain to cultivate biomass energy plants provide a broad space. The Eulerium is a kind of ecological, economic, social benefits of a high degree of unity of the tree species. In this paper, the biology characteristics, breeding and afforestation techniques, extraction and purification of essential oil, and the problems in the development and utilization of Litsea cubeba resources were summarized. The aim of this study was to provide a reference for the future development and utilization of Litsea cubeba resources .

In this experiment, we compared the strength of three kinds of vegetable oil and Litsea cubeba oil with peanut oil, soybean oil and pepper oil. Peanut is one of the major economic oil crops in China, because its main fatty acid composition and olive oil similar, so "the Chinese people's economic olive oil," peanut oil content of up to $50 \%$, peanut oil because of the large amount of unsaturated fatty acids It is easy to be oxidized, but at the same time, peanut oil has some antioxidant activity because it contains antioxidant components such as VE, phytosterols and squalene, and the research on endogenous antioxidants in peanut oil is attracting more and more attention. Soybean oil is a kind of soybean oil, soybean oil, high nutritional value, rich in raw materials, but also one of China's major edible oil ${ }^{[3]}$. Soybean oil contains natural pigments, vitamin $\mathrm{E}$ and other natural antioxidants, and thus also have some antioxidant properties. Pepper oil is a 
natural volatile oil extracted from pepper seed and seed coat. The pepper oil is rich in flavonoids, phenols, aldehydes, saponins, tannins, alkaloids and polysaccharides And other substances are considered to have a certain degree of antioxidant capacity. In the present literature, there are many reports on the research on the antioxidant activity of the pepper oil ${ }^{[4]}$. Xu Kun et al. Explored the antioxidant activity of the pepper oil by the inhibition of hydroxyl radical and superoxide radicals. It was proved that the pepper oil Strong antioxidant effect, and its antioxidant and the reduction force between the linear correlation. Huang Jing Shi et al through experiments, found that peanut oil in peanut oil can effectively slow down the oxidation rate of peanut oil, thereby enhancing the antioxidant stability of peanut oil. Therefore, the antioxidant activity of Litsea cubeba oil has a certain value compared with the three kinds of oil on the oxidation resistance of Litsea cubeba oil ${ }^{[5]}$.

In this paper, the antioxidant capacity of Litsea cubeba oil was determined by reduction force method, and the reducing power of Litsea cubeba oil, peanut oil, pepper oil and soybean oil was stronger than that of Litsea cubeba oil Oxidation of the study.

\section{Materials and Methods}

Materials of the Test. Litsea cubeba fruit: Place of origin was Anhui Province, China; Absolute Alcohol: Tianjin Fu Yu Fine Chemical Co., Ltd.;

Experimental Apparatus. Swing High-speed Universal Pulverizer: Wenling Grand Forestry Machinery Co., Ltd.; AY120 Electronic Analytical Balance: Shimadzu Corporation; KH-400KDB High Power CNC Ultrasonic Cleaner: Kunshan Hechuang Ultrasonic Instrument Co.; SHZ-D (III) Circulating Water Pumps: Gongyi Instrument Co., Ltd.; RE-52AA Rotary Evaporator: Shanghai Yarong Biochemical Instrument Factory.

\section{Determination of Reduction Force}

(1) The preparation of the solution

$1 \%$ potassium ferricyanide solution: take $1.0 \mathrm{~g}$ potassium ferricyanide with distilled water completely dissolved to $100 \mathrm{~mL}$, placed in a brown bottle to save. $10 \%$ trichloroacetic acid: weighed $10 \mathrm{~g}$ trichloroacetic acid dissolved in $90 \mathrm{~g}$ distilled water can be. $\mathrm{HCl}$ solution $(2.5 \mathrm{mmol} / \mathrm{L})$ : take $0.021 \mathrm{~mL}$ concentrated hydrochloric acid can be set to $100 \mathrm{~mL}$. $0.1 \%$ ferric chloride solution: Weigh $0.1 \mathrm{~g}$ of ferric chloride, dissolved in $2.5 \mathrm{mmol} / \mathrm{L} \mathrm{HCl}$ solution, set to $100 \mathrm{~mL}$, placed in a brown bottle to save. Phosphate buffer (0.2 mol / L, pH 6.6): Take $0.2 \mathrm{~mol} / \mathrm{L} \mathrm{Na}_{2} \mathrm{HPO}_{4} 31.5 \mathrm{~mL}$ and 0.2 $\mathrm{mol} / \mathrm{L} \mathrm{NaH} \mathrm{PO}_{4} 68.5 \mathrm{~mL}$, mix well and adjust the $\mathrm{pH}$ to 6.6 with $0.1 \mathrm{~mol} / \mathrm{L} \mathrm{NaOH}$ and $\mathrm{HCl}$ (Corrected with $\mathrm{pH}$ meter).

(2) Preparation of Litsea cubeba oil emulsion

The general operation of phase-shifting emulsification is to prepare the surfactant and the oil phase at the process temperature, and then the mixture will be heated to the same The temperature of the water droplets into the oil phase under the liquid, under reasonable stirring into the W/O emulsion. Then cooled to phase, or increased water content to phase into $\mathrm{O} / \mathrm{W}$ emulsion. The former is called temperature transversion method (PIT method), which is called emulsion phase method (EIP method). In this experiment, the EIP method was used to accurately weighed $0.8 \mathrm{~g}$ of Litsea cubeba oil, $0.3 \mathrm{~g}$ of Tween- 80 was added, and the mixture was thoroughly mixed at $40{ }^{\circ} \mathrm{C}$, and then distilled water heated to $40^{\circ} \mathrm{C}$ was added to $100 \mathrm{~mL}$ while stirring.

(3) Determination method

The emulsions of Litsea cubeba oil with oil concentration of $8 \mathrm{mg} / \mathrm{mL}$ were diluted with distilled water to $35 \%, 45 \%, 55 \%, 65 \%$ solution containing Litsea cubeba oil emulsion. $1.0 \mathrm{~mL}$ of the above diluted littoral oil solution was added to $2.5 \mathrm{~mL}$ of $0.2 \mathrm{~mol} / \mathrm{L}$ phosphate buffer ( $\mathrm{pH}$ 6.6) and $2.5 \mathrm{~mL}$ of $1 \%$ potassium cyanide solution. The mixture was incubated at $50^{\circ} \mathrm{C}$ for 20 min and then $2.5 \mathrm{~mL}$ of $10 \%$ trichloroacetic acid was added to the reaction mixture. After mixing, the mixture was centrifuged at $3000 \mathrm{rpm}$ for $10 \mathrm{~min}$. Purified with $2.5 \mathrm{~mL}$ of distilled water and $2.5 \mathrm{~mL}$ of $0.1 \%$ ferric chloride The reaction was carried out in vitro, and the absorbance at $700 \mathrm{~nm}$ was measured after $10 \mathrm{~min}$. Distilled water was used as blank control.

Comparison of the Reducing Force of Litsea Cubeba Oil and Other Common Vegetable. The extraction method of peanut oil, pepper oil and soybean oil was the same as that of Litsea 
cubeba oil. The extraction method was 3.2 .1. Reduction force determination method such as 3.3.2, the mass concentration of $8 \mathrm{mg} / \mathrm{mL}$ four kinds of oil emulsion diluted into $75 \%$ of the oil emulsion solution, respectively, take $1 \mathrm{~mL}$, determine the reduction force, and then compare.

\section{Results and Discussion}

\section{Reducing Force of Litsea Cubeba Oil}

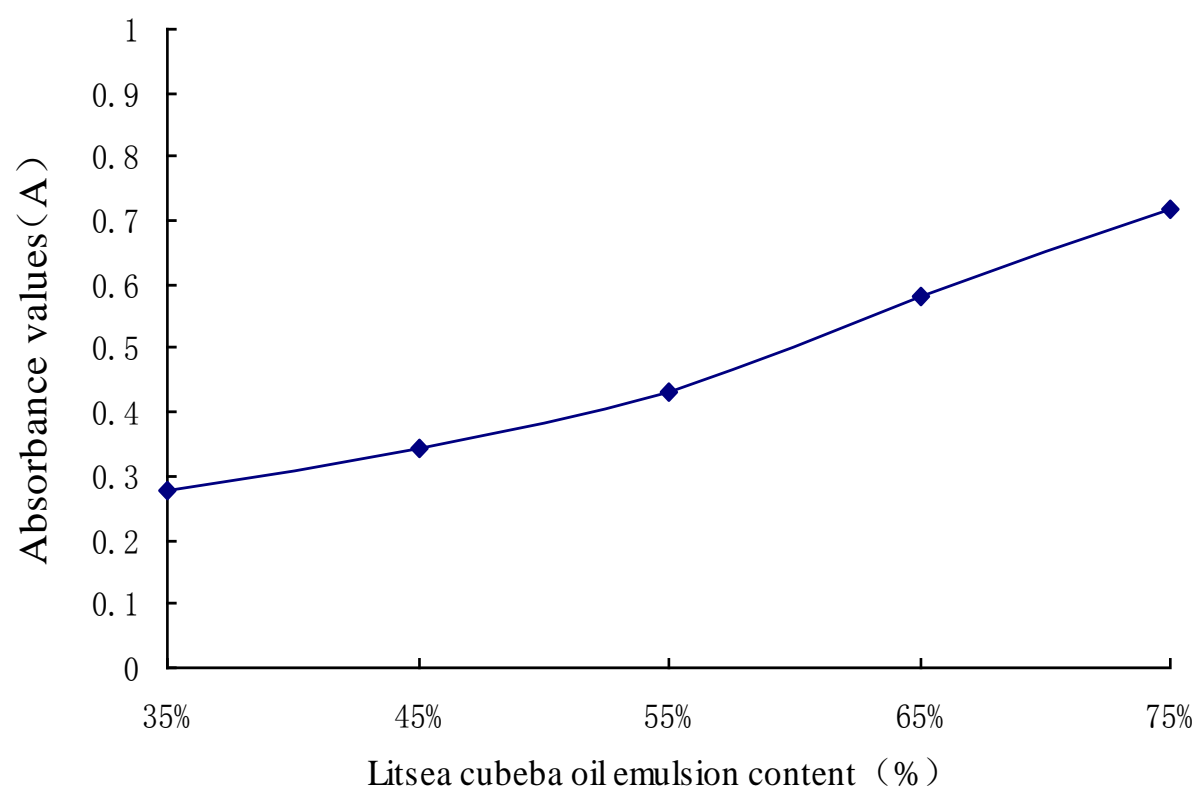

Figure 1. Determination of the reducing power of Litsea cubeba oil emulsion with different percentages

It can be seen from Fig. 2 , within a certain range, the higher the percentage of Litsea cubeba oil emulsion, the greater the absorbance value, fitting Litsea cubeba oil emulsion content and 700nm absorbance value of the correlation curve, Regression equation: $y=1.124 x-0.1472(\mathrm{R} 2=0.9759)$, the correlation between the two strong. The results showed that the reducing force of different concentrations of Litsea cubeba oil could be explained to a certain extent. When the content of Litsea cubeba oil emulsion was $35 \%$, the concentration of Litsea cubeba oil was $2.8 \mathrm{mg} / \mathrm{mL}$ and the absorbance was only 0.276 . When the content of Litsea Cubeba Oil was 75\%, the concentration of Litsea cubeba was $6 \mathrm{mg} / \mathrm{mL}$, the measured absorbance value has been as high as 0.719 . The results showed that the total reducing power of Litsea cubeba oil was stronger than that of Litsea cubeba oil, and the total restoring force of Litsea cubeba oil increased linearly with the increase of concentration. The ability of the decoction of Litsea cubeba oil indicates that Litsea cubeba oil has a good electron donor component that can terminate the free radical reaction chain by converting the free radical into a more stable product and has a certain antioxidant capacity. As the antioxidant reduction force stronger, its antioxidant capacity is stronger, therefore, the greater the concentration of Litsea cubeba oil, the higher the antioxidant capacity.

\section{Litsea Cubeba Oil and the Other Three Commonly Used Oil Reduction Force Comparison Results}

Litsea cubeba oil and peanut oil, soybean oil and pepper oil to restore the strength of the results are as follows: 


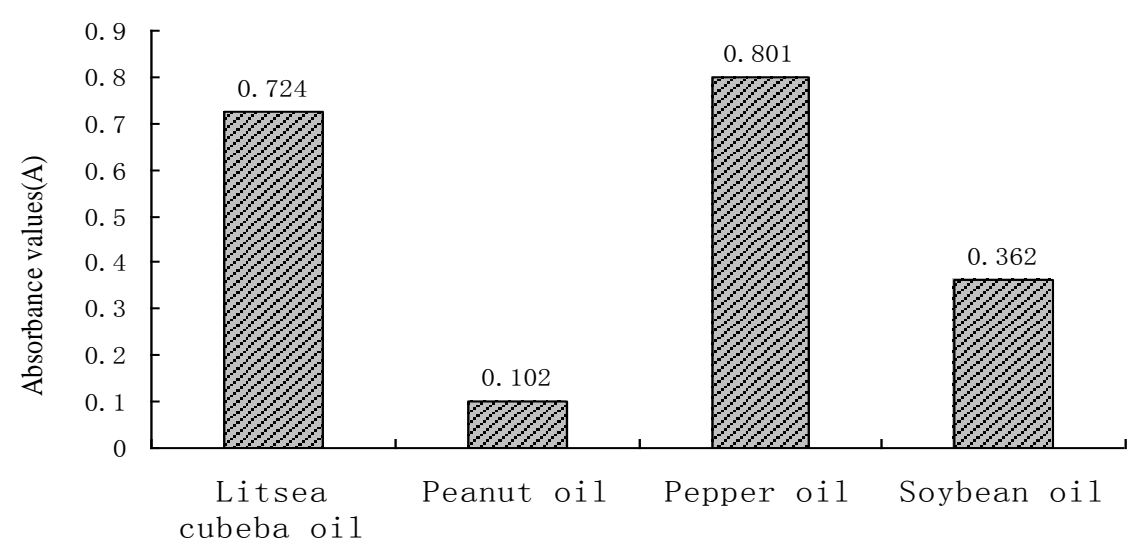

Figure 2. Litsea cubeba oil, peanut oil, pepper oil and soybean oil reduction force size

From the experimental results, these four kinds of oil in the same mass concentration have a certain reduction force, their ability to restore the size of the order: pepper oil> Litsea cubeba oil> soybean oil> peanut oil. When the percentage of oil emulsion is $75 \%$, the mass concentration of oil is $6 \mathrm{mg} / \mathrm{mL}$. When the mass concentration of Litsea cubeba oil, peanut oil, soybean oil and pepper oil were $6 \mathrm{mg} / \mathrm{mL}$, the reducing power of peanut oil and soybean oil was lower, and the absorbance of peanut oil was only 0.102 at 700nm, 0.362. Compared with peanut oil and soybean oil, the yield of Litsea cubeba oil and pepper oil was 0.724 and 0.801 , respectively. The reduction ability of Litsea cubeba oil was slightly lower than that of pepper oil. The results showed that the antioxidant activity of the pepper oil was the strongest, and the two kinds of oil had strong antioxidant effect, while the antioxidant capacity of the peanut oil and the soybean oil were Weak, which is the weakest antioxidant peanut oil, soybean oil than its slightly stronger.

\section{Conclusion}

The determination of reducing ability of Litsea cubeba oil showed that Litsea cubeba oil had strong antioxidant effect, and the restoring force was linearly related to the concentration of Litsea cubeba oil. The concentration of Litsea cubeba oil was bigger, The stronger the ability, so the stronger the antioxidant. The yield of four kinds of vegetable oil was higher than that of the four kinds of vegetable oil. The antioxidant activity of the pepper oil was the strongest, and the antioxidant activity of the pepper oil was the highest, Litsea cubeba oil antioxidant effect is better, and soybean oil and peanut oil followed.

\section{Acknowledgements}

This work is supported by Guangdong Province Science and Technology Project(No. 2016A020210133)

\section{References}

[1] Huang Z. J., Gotoh M., Hirose Y . Improving sinterability of ceramics using hybrid microwave heating[J].Journal of Materials Processing Technology, 2009, 209(5): 2446-2452.

[2] Kudra T., Raghavan CZ S. V, Voort F. R. Microwave heating characteristics of rutile[J]. Journal of Applied Physics, 1993, 73(9): 4534-4540.

[3] Huang K. M., Yang X. Q., Hua W., et al. Experimental evidence of a microwave non-thermal effect in electrolyte aqueous solutions[J].New Journal of Chemistry, 2009, 33(7): 1486-1489. 
[4] Navarrete A., Wallraf S., Mato R. B., et al. Improvement of essential oil steam distillation by microwave pretreatment[J]. Industrial and Engineering Chemistry Research, 2011, 50(8): 4667-4671.

[5] Ji J., Deng C. H., Zhang H. Q., et al Microwave-assisted steam distillation for the determination of organochlorine pesticides and pyrethroids in Chinese teas[J].Talanta, 2007, 71(3):1068-1074. 